\title{
Formação de professores: aportes multiculturais e o movimento da inclusão
}

\section{Formation of teachers: multicultural approaches and movements of inclusion}

\author{
Roseli Cecília Rocha de Carvalho Baumel*
}

\begin{abstract}
RESUMO
Este artigo pretende abordar direções que ofereçam aportes sobre a formação de professores, na compreensão do multiculturalismo - é ele o espaço da diversidade? - e, a inclusão, que tem sido contemplada em embates internacionais (Unesco, 2001), como chave das ações humanas e, muito mais, profissionais. Uma questão norteia essas abordagens: - É a diversidade o elemento constituinte na necessária reconstrução e reedificação dos programas formativos dos professores? Para tanto, é necessário discorrer sobre esses temas centrais que elegemos, situando: a formação de professores e o multiculturalismo - como espaço das relações interpessoais: alteridade (SKLIAR, 2003) e, possíveis articulações com a inclusão, termo que se tornou quase um slogan do atual quadro educacional e social. O "interculturalismo" aparece como alternativa de formação ao professor e superação de visões reducionistas sobre a diversidade cultural com que trabalha hoje.

Palavras-chave: multiculturalismo, inclusão, diversidade, interculturalismo.
\end{abstract}

\begin{abstract}
This article intends to approach different ways of understanding the formation of teachers, by the comprehension of multiculturalism - is it a space of diversity? - and inclusion, which has been contemplated in international debates (Unesco, 2001) as a key-concept for human actions,

* Professora livre-docente da Universidade de São Paulo - USP. E-mail: rbaumel@usp.br
\end{abstract}


specially the ones related to professional life. A question directs these approaches: Is diversity the constituent element in the necessary reconstruction and rebuilding of the teacher's formative programs? For that, it necessary to consider the main topics chosen here, pointing out: multiculturalism - as a space for interpersonal relations -, alterity (SKLIAR, 2003), and possible articulations with inclusion - almost a slogan in the current educational and social picture.

Key-words: multiculturalism, inclusion, diversity, interculturalism.

\section{Introdução}

No âmbito da produção de conhecimento na educação, alguns temas têm sido privilegiados, abrindo horizontes para discussões e análises dos profissionais da área, divisando relevantes problemas investigativos. MOREIRA (1999) aponta entre eles, uma preocupação fundamental hoje no que se refere à formação de professores e o currículo como objeto e instrumento do trabalho docente, considerando a complexidade das novas configurações sociais presentes na escola .

Assim, seja para professores ou formadores, as abordagens sobre a formação inicial e continuada em atendimento às complexas tarefas da função docente no contexto atual voltam-se para as vertentes e concepções que trazem a reflexão na ação e o desenvolvimento profissional como dimensões de crucial importância, que demandam aprofundamentos e análises criteriosas de seus aspectos constitutivos.

No âmago dos questionamentos sobre esses temas, um se destaca e aponta para a busca de respostas em torno do preparo, atuação e desenvolvimento dos professores: a diversidade, como compreensão oposta aos propósitos da homogeneização histórica da educação formal, como impossibilidade humano-social na escola e na sala de aula, a ser verificada na realidade da prática escolar.

Propomos nesta abordagem portanto, discutir as questões da diversidade no sentido de situar as possibilidades e opções no trabalho e formação docente, a partir de reflexões e discernimentos sobre as idéias de inclusão e multiculturalidade que levem à busca de uma atitude intercultural na complexa tarefa da formação humana hoje. 


\section{Formação de professores}

Para tomar um ponto de partida nessa questão, é necessário situar a mudança educativa, tão reclamada e que no contexto atual tem no professor um forte componente e ator. No dizer de Parrilla (1999) "o profissional da educação, mais que um trabalhador que opera e aplica técnicas rigorosas, específicas e cientificamente fundamentadas sobre os alunos, é um profissional da mudança educativa que sabe, aprende a enfrentar alternativas singulares, específicas e concretas que cercam os problemas e necessidades únicas que exigem respostas às mesmas".

A questão crucial, segundo o autor, é a mobilização da escola e dos professores em torno das escolhas entre o tradicional e o novo, que pode mobilizar esforços em "esquemas e desenvolvimento de processos abertos e flexíveis", com a criação de contextos e situações construídas a partir da diversidade. O trabalho assim divisado coloca o currículo como "âmbito de desenvolvimento e intervenção privilegiada" em que o professor é figura central, que constrói, reorienta, engendra o processo pedagógico em função de novas demandas sociais.

Ao situar o professor como centro de todo o programa formativo, faz se necessário apontar algumas questões nesse processo. A formação, como uma dimensão fundamental, passa a ser vista como elemento-chave dos consensos e dos conflitos, por países que analisaram a inclusão sob a chancela da Unesco (2002): de um lado, consenso, no que tange à argumentação sobre as possibilidades e impossibilidades do professor trabalhar frente às demandas das necessidades dos alunos; de outro lado, conflito, porque há incompreensões quanto às políticas sobre formação dos professores.

Há que se pensar que o ponto frágil está centrado no desenvolvimento profissional que é obscuro ou é ignorado nessas políticas. A clareza das políticas, neste campo, deve se referir às concepções sobre a formação inicial (nas Instituições de Educação Superior) e a continuada - como investimento, nos sistemas do Estado.

MARCELO GARCÍA, 1999 referencia as categorizações conceituais que têm se manisfestado como tendências sobre a formação dos professores:

1) orientação prática - que tem no centro a experiência como fonte básica da aprendizagem que é obtida na prática. Os referenciais teóricos existem, mas sem propósitos da reconstrução crítica e retomada da prática. Assim, currículos elaborados e implementados em ampliados períodos práticos (com o argumento de integrar a teoria 
à prática) põem a risco uma desconectada prática em relação à própria instituição formativa;

2) orientação acadêmica - que concebe a formação dos educadores como um processo de domínio de conhecimentos científico-culturais, dos conceitos das diversas áreas/matérias que compõem o currículo. O propósito é o desenvolvimento de profissionais eruditos e peritos. Aqui se exemplifica a formação de especialistas, que não exclui referências gerais (que dão sentido à especialização).

3) orientação tecnológica - que se localiza no campo das competências. Estas, em uma concepção prática, se constituem como aplicações do conhecimento científico e detalhado em "regras de atuação. É uma espécie de tecnologia pedagógica" - como guia e direção da prática, imprevisível, singular - que pode expor fragilidades e críticas. Como o afirma (MARCELO GARCíA, 1999), o importante é que o professor, intelectualmente capacitado, selecione e decida qual a competência mais apropriada a cada situação com que se depara, na sua prática;

4) orientação personalista - que admite ser a formação, um processo de transformação e desenvolvimento pessoal. O desenvolvimento profissional se centraliza em um caráter individual e pessoal - uma formação em atitudes. Não se pode deixar de assinalar que é um marco conceitual, de referência sensível, mas pode evidenciar insuficiência como orientação global;

5) orientação social reconstrucionista - perspectiva que tem se fortalecido como superação da racionalidade técnica, de insistente força na formação dos professores.

O autor propõe uma perspectiva crítica, em que a reflexão se torna instrumento básico de aprendizagem. A reflexão não é concebida como análise técnica ou prática, mas deve incorporar componentes, como socialização em que a reflexão deve ser socializada, coletivizada; compromisso ético e social de busca e análise das práticas educativas e sociais democráticas e propósitos plantados nos interesses humanos, políticos e sociais, tanto particulares como coletivos.

Cabe neste ponto perguntar: - Se as concepções sobre a formação docente invocam considerações éticas e políticas, que estão imbricadas na questão também cultural, qual é o lugar da cultura neste processo formativo? Parece que há consensos sobre a clareza da idéia que se deve ter sobre cultura para desenvolver a educação formal escolar. A partir da diversidade cultural com que o professor trabalha hoje, muito se tem comentado sobre a visão multicultural como necessária à prática escolar com os grupos sociais. Propomos assim, adentrar as tendências conceituais presentes nessa área. 


\section{Multiculturalismo}

Esse tema tem sido objeto de questionamentos, análises e produções no campo educacional, trazendo grande contribuição aos novos parâmetros para a formação de professores. Pensamos que, por isso, necessita de constante reavaliação de pressupostos, aprofundamentos e ponderações críticas. MOREIRA ressalta a importância da cultura na dinâmica social (MOREIRA, 1999; CANDAU, 2002), na qual se insere a significação do mundo social, das relações formais e informais. Para CANDAU, que reforça essa tese, a cultura é o "núcleo da identidade dos grupos sociais dos povos de uma nação".

MOREIRA ressalta a cultura como "esfera de lutas, de diferenças, de desigualdades", de poderes hierárquicos. Assim, as diferenças que se evidenciam - de raça, classe social, gênero, linguagem, capacidade e cognições - têm justificado lutas, preconceitos, discriminações sofridas pelos indivíduos, grupos e comunidades. De um lado, o mundo de desigualdades, de contradições alerta para pólos radicais, chamados em discursos (notadamente no campo educacional), em termos de afirmações locais, ortodoxas, xenófobas, e de outro lado, a voz da igualdade, num esforço de naturalização das situações individuais essencializadas - todos são iguais, todos têm direitos iguais.

Dessa forma, ao se refletir sobre formação e atuação dos professores, não se pode relegar a um plano secundário ou menos importante a cultura enquanto visão multicultural. Ela está latente, presente na escola, nas salas de aula, nas atividades e alternativas pedagógicas do coletivo escolar, fortalecendo ou enfraquecendo (de acordo com a concepção adotada) as interações, as ações dos indivíduos e mais, dos professores (MOREIRA, 1999).

Em relação à presença e formas de ver e lidar com os grupos culturais em uma sociedade, MOREIRA aponta as posições vigentes, que podem nos esclarecer na busca de atitudes a serem adotadas no processo cotidiano da escola hoje:

- multiculturalismo conservador, que pressupõe situações de inferioridade, e a coexistência de uma elite capaz, competente, tomando as rédeas da cultura comum, dominante. Assim, há grupos subordinados, há hegemonia e homogeneidade do capital cultural da classe dominante em que os dominados sofrem explorações e preconceitos não velados;

- $\quad$ multiculturalismo liberal, que concebe igualdade entre raças, situações de deficiência de qualquer ordem. Essa concepção aceita normas e valores sob o rótulo de igualdade natural entre os homens. As situações desiguais resultam da falta de oportunidades sociais, educacionais e/ou de outra natureza; 
- $\quad$ multiculturalismo liberal de esquerda, que ressalta as diferenças culturais, essencializando-as, naturalizando-as. De toda forma, há aqui a defesa de uma situação única, uma forma única, reforçando o diferencialismo (SKLIAR, 2003), como um novo tipo de igualitarismo que se centra em cada traço, cada parte do rosto, da fala. MOREIRA explica que, nessa perspectiva, há uma omissão da produção histórica e social das identidades, ao mesmo tempo em que ressalta características essenciais que diferem de uma situação a outra;

- multiculturalismo crítico, o qual rejeita a igualdade e os pontos de diferenciação. Assim, a diferença existe, sendo produto da história, da cultura, da ideologia, das relações de poder (MOREIRA, 1999) e nessa perspectiva, o importante ponto a ressaltar é o interculturalismo, como processo de diálogo e partilha entre culturas.

Outra vertente fundamental refere-se à importância do multiculturalismo como "espacialidade do outro", e é esclarecida por SKLIAR (2003) a partir das considerações sobre alteridade e mesmidade. Assim, segundo o autor, o espaço multicultural tem uma gramática, e pode ser explicado ou definido:

- como consciência coletiva oponente aos centrismos: etno, fono...

- como nova teorização sobre o outro, num esforço de compreensão cultural, política, cidadania e educação;

- como "ações afirmativas" - com o propósito de promover a igualdade de oportunidades sociais, políticas, econômicas, culturais;

- em forma de lutas e movimentos pela alteridade, pelo olhar e conviver com o outro;

- como consideração da diversidade para descrições políticas, educativas, lingüísticas;

- como enunciação e defesa explícita de políticas que envolvam a identidade e a diferença.

O autor aponta, com voraz crítica, que a citada gramática do multiculturalismo se enreda em nomes, terminologias, referências às noções de cultura, identidade, diversidade e diferença. Estas noções são indicadas, argumentadas e trabalhadas no tema atual que circula em discussões, produções e práticas educacionais: a inclusão. 


\section{Inclusão}

A inclusão, com seus vários qualificativos que vão do escolar ao social, tem sido tratada em acordos internacionais, leis federais, estaduais e municipais (Dakar, Madri, Guatemala, Sapporo - no cenário internacional) e é desafio a ser enfrentado no plano político, ou seja, nas bases das ações governamentais.

É preciso que, em torno da tarefa desenvolvida pelos países, no alcance desse propósito, e até na busca de mudanças, discutir que inclusão implica discussões sobre exclusão (SKLIAR, 2003). O autor reforça a idéia citando CASTEL (apud GENTILI, 2001), alertando para a construção e a produção da exclusão por três mecanismos:

- o aniquilamento - a exclusão pelas lutas entre comunidades étnicas, massacres;

- $\quad$ a separação institucional - no afastamento, na distância do outro;

- a inclusão - aproximação que se traduz em aniquilamento do outro.

Acrescente-se um indicador, adotado no bojo das políticas sociais, que é o estatístico. Neste, a exclusão é analisada a partir de percentuais relativos à evasão e reprovação escolar e ainda como não usufruto de bens mínimos para a sobrevivência dos cidadãos, por exemplo, alimentação, infra-estrutura sanitária, saúde e outros.

No âmbito educacional, destacam-se análises sobre a situação da inclusão, entre elas a das autoras SALEH e VÄRYNEN (2000), que a caracteriza como uma nova agenda, que atente para a identificação de todas as formas de exclusão e barreiras sociais, notadamente.

As autoras afirmam, com ênfase, sobre a urgência da identificação dessas restrições, principalmente na aprendizagem, e que essa perspectiva deve ser tratada no interior de políticas nacionais, culturais, instituições educacionais e comunidades. Acrescentam ainda três pontos, a partir das experiências dos países que têm intentado propostas educacionais inclusivas, para se refletir e concretizar a "nova agenda":

\section{Consensos}

Alguns fatores se revelaram como consensuais:

- $\quad$ o sentido das políticas que, em alguns casos, não aclaram princípios inclusivos e não incentivam mobilizações para a inclusão; 
- os recursos/fundos públicos nos quais são consideradas as diferentes perspectivas ou modelos de financiamento, com descentralizações/centralizações que acabam por restringir ou agilizar programas inclusivos;

- $\quad$ as discussões sobre currículo, que envolvem a preparação dos professores para a inclusão e que respondem a exigências em torno do trabalho com os conteúdos, nas adaptações curriculares, na compreensão do acesso dos alunos ao conhecimento hoje;

- a formação dos professores em que as propostas oficiais educacionais apontam discussões necessárias e urgentes sobre a formação inicial e em serviço (continuada) na direção do preparo para trabalhar em meios/ ambientes pedagógicos visando à inclusão;

- os serviços de apoio como suporte às ações do professor constituem-se em ponto crucial ao desenvolvimento de práticas inclusivas. Esses serviços internos e externos à escola chegam a tomar as funções das chamadas redes de proteção social, mobilizando a inclusão no seu amplo sentido;

- o envolvimento da família nas abordagens colaborativas em que esta é cada vez mais requisitada, e, na análise da inclusão, é um dos fatores de mudança dos mais importantes (AINSCOW, 1998);

- a colaboração multisetorial como ponto de convergência entre os profissionais voltados ao desenvolvimento humano, em um contexto intersetorial e colaborativo.

\section{Conflitos}

Os países interessados no processo de inclusão, pela via educacional, citam em torno de suas políticas, conflitos que devem ser analisados, reconsiderados. Primeiramente, no que se refere a Fundos Públicos, o investimento de recursos em torno da segregação ou da inclusão nem sempre está claro ou disponível. Esses recursos são apontados no conjunto dos conflitos, e esse procedimento pode viabilizar facilitações ou obstruções às práticas inclusivas. O outro ponto, com respeito à formação de professores, que é fundamental, necessita a revisão de programas à luz de políticas educacionais que considerem o significado de desenvolvimento profissional, que discutiremos mais adiante.

\section{Barreiras e desafios}

Pode-se situar nessa perspectiva diversas naturezas de barreiras: as atitudinais, físicas e pedagógicas por um lado, e, por outro, as culturais, que 
têm fundamento na formação dos professores, nas suas condições de trabalho, na existência ou não de suporte estrutural para a função, entre outros.

Os desafios a serem encarados para tornar a inclusão uma tarefa concreta e competente, segundo SALEH e VÄRYNEM (2000), centram-se em algumas ações fundamentais:

- $\quad$ desenvolver uma filosofia de inclusão, em tempos de transição;

- $\quad$ articular inclusão para amplas dimensões, o que exige considerar o espectro cultural de cada realidade e a compreensão do significado de diferença e diversidade;

- mobilizar opinião, seja em organizações profissionais, pesquisas, programas formativos, mídia e canais de comunicação.

Neste ponto de nossa abordagem é importante refletir sobre os termos diversidade, diferença, identidade e tolerância. Se esses termos compõem o espectro argumentativo sobre educação inclusiva, ensino inclusivo, escola inclusiva, práticas inclusivas, há necessidade de uma reflexão apurada sobre tais processos, buscando possíveis articulações entre formação de professores, multiculturalismo e inclusão, levando em conta que diversidade tem referência no âmbito da cultura $e$ diferença tem referência no âmbito da identidade de cada sujeito.

Essa constatação leva a defender a idéia de que mudanças na formação dos professores, na adoção da inclusão que desestabiliza, desestrutura a escola, tem a ver com desenvolvimento profissional, o qual inclui mudanças de atitudes nas práticas de sala de aula e do próprio professor, exigindo repensar matrizes formativas a partir da compreensão da diversidade e, por força, da cultura.

Para tal intento, é necessário repensar algumas questões cruciais:

- a consideração, pelos professores, de questões sobre $o$ sentido e a redefinição dos propósitos da educação escolar, no enfrentamento de temas como gênero, identidade, ética e direitos humanos (MOREIRA, 1999);

- a análise de uma nova cultura educativa da diversidade, a partir de contradições entre teorias e práticas reais, e isso fica evidente no custo da incorporação e traduções da diversidade, na sala de aula, na escola;

- $\quad$ estabelecer diálogos interculturais, o que exige construir e reconstruir habilidades de crítica, autocrítica e auto-avaliações, em toda a formação dos professores;

- análise, pela escola, pelos professores, do conhecimento cultural produzido, usado, para interpretar conhecimento social, por um gru- 
po: [a gramática do(s) outro(s)], articulando-o com o conhecimento objetivado pela escola. É possível, assim, desvelar tensões, contradições e descontinuidades presentes nas dinâmicas sociais.

O desafio consiste em desenvolver capacidades comunicativas no e para o diálogo, pelos professores. Como afirma ARROYo (2002), há que ser desenvolvida a escuta atenta e renovada da realidade, tanto na formação inicial, continuada e na autoformação, para buscar:

- $\quad$ reconceitualização do singular, do concreto, do diverso, que não podem ser respondidos a partir da regra, da técnica, da norma (PARRILLA, 1999);

- $\quad$ ressituar os parâmetros das respostas à diversidade, a partir do marco institucional às situações não formais;

- $\quad$ partir da diversidade como pano de fundo da educação, sendo que qualquer situação educativa parte e é ponto de chegada que se funda na compreensão da diversidade.

A mudança exigida no quadro exposto não depende só dos professores, mas da sua formação atitudinal, conceitual e processual - uma formação integradora - de atitudes frente à diversidade como alternativa cultural: conteúdos conceituais; conteúdos procedimentais, processuais (saber fazer); conteúdos atitudinais (desenvolvimento pessoal - resistência, expectativas, experiências, percurso de vida); conteúdos práticos (história profissional, experiência pedagógica).

Para MARCELO GARCíA, 1999: "a educação, a formação intercultural diz respeito à necessidade de integrar o conceito de diversidade nos conteúdos e métodos de ensino, pois diz respeito às questões de raça, gênero, capacidades".

Em síntese, podemos pensar em fundamentos para uma formação de professores, calcada na análise das concepções sobre cultura e diversidade existente em grupos sociais presentes na instituição escolar, em termos de:

1 - conhecimento sobre desenvolvimento organizacional: gestão escolar, cultura, micro e macropolítica, liderança, clima relacional;

2 - conhecimento sobre desenvolvimento e inovação curricular: reorientação do currículo no que se refere a Concepções; Poder, Ideologia e Cultura;

3 - conhecimento sobre ensino: formas de coordenação e relação pedagógica (estruturas metodológicas e alternativas pedagógicas); social (comunicação); acadêmica (tarefas); cognitiva (reflexão, aprendizagem, construção de conhecimento, avaliação);

4 - conhecimento pessoal: profissionalidade, desenvolvimento profissional, condições de ensino psicológicas e sociais; histórias de vida, autobiografias. 


\section{Concluindo}

Ao finalizar, sugerimos a discussão das vivências e práticas culturais das escolas, alertando para os perigos das aplicações dos conceitos e práticas do multiculturalismo (CANEN, 2002), em especial, as práticas curriculares que, em nome de crítica e inovações, perpetuam preconceitos e reforçam discriminações. A autora cita, em torno desses perigos, algumas propostas, desenvolvidas pelas escolas, no intento de reparar injustiças: - o multiculturalismo reparador; o folclorismo; o reducionismo identitário e guetização culturais.

$\mathrm{Na}$ formação do professor hoje, esses reducionismos podem ser superados pela visão intercultural a que já nos referimos e que gostaríamos de enfatizar. Trabalhar numa perspectiva intercultural, inclui a consciência da presença na sociedade de diferentes grupos culturais, que interagem permeados por relações de poder historicamente construídas e marcadas por estereótipos raciais, de gênero e outros. Quando o "outro", o "diferente" se revela em toda a sua concretude, pode ser uma descoberta altamente ameaçadora em que comportamentos e dinâmicas sociais passam a construir "muros" que, física e ideológicamente provocam apartheids sociais e culturais, processos de guetificação, que nas cidades latino-americanas cada vez mais se acentuam. (CANDAU, 2002, p. 97). O caráter multicultural não leva necessariamente ao desenvolvimento de uma dinâmica social que mobiliza processos interculturais como viemos constatando.

Uma postura intercultural pressupõe deliberada inter-relação entre os diferentes grupos socioculturais. Encaminha e constrói diálogos entre as raças, gênero, capacidades, de forma crítica, não ingênua. Essa é, para CANDAU (2002), uma perspectiva de inter-relação que afeta a educação em todas as suas dimensões, favorecendo uma atitude de crítica e autocrítica, valorizando a interação e comunicação recíproca entre os indivíduos. A interculturalidade orienta processos que têm por base o reconhecimento do direito à diferença $\mathrm{e}$ a luta contra todas as formas de discriminação e desigualdade social. Tenta promover relações dialógicas e igualitárias entre pessoas e grupos que pertencem a universos culturais diferentes, trabalhando conflitos inerentes a esta realidade. É um processo permanente, inacabado, que promove relações democráticas entre os grupos e não somente a existência pacífica entre eles. (CANDAU, 2002)

Para CANDAU, a educação intercultural não pode ser reduzida a algumas situações ou atividades realizadas em momentos específicos ou por determinadas áreas curriculares, nem focalizar sua atenção exclusivamente em deter- 
minados grupos sociais. Trata-se de um enfoque global que deve afetar a cultura escolar como um todo, e a todos os envolvidos nas dimensões do processo educativo, em cada uma das escolas e sistemas de ensino. Diz respeito, por isso, às políticas oficiais educacionais, afetando aspectos pedagógicos do currículo explícito e oculto trabalhado pelo professor e suas relações com os diferentes agentes a que se destina direta ou indiretamente: professores, coordenadores, alunos, pais, agentes comunitários etc. Diz respeito à construção de relações democráticas e à superação do autoritarismo fortemente arraigado nas culturas latino-americanas.

Uma educação intercultural é um desafio que exige problematizar diferentes elementos da cultura escolar no entendimento de questões que têm a ver com as funções da escola hoje. A proposta que fazemos ao finalizar esta abordagem é de que a visão intercultural possa ser constitutiva dos cursos de formação e desenvolvimento profissional do professor, no sentido de dar suporte à sua função e desenvolvimento profissional frente às exigências da formação humana na atualidade.

\section{REFERÊNCIAS}

AINSCOW, M. Caminhos para a Escola Inclusiva. Lisboa: Instituto de Inovação Educacional, 1998.

ARROYO, M. Ofício de mestre. Imagens e auto imagem. Petrópolis: Vozes, 2002.

CANEN, A. Sentidos e dilemas do multiculturalismo: desafios curriculares para o novo milênio. In: LOPES, A. C.; MACEDO, E. Currículo: debates contemporâneos. São Paulo: Cortez, 2002.

CANDAU, V. M. (Org.). Sociedade, educação e cultura(s): questões e propostas. Petrópolis: Vozes, 2002.

GENTILI, P. Pedagogia da exclusão. Petrópolis: Vozes, 2001.

MARCELO GARCÍA, C. Formação de professores para uma mudança educativa. Lisboa: Porto Editores, 1999.

MOREIRA, A. F. et al. (Org.). Currículo: políticas e práticas. Campinas: Papirus, 1999.

PARRILLA, A. L. La Formación de los Profesionales de la Educación Especial y el Cambio Educativo. Educar, Barcelona, v. 21, p. 39-65, 1997. 
SALEH, L.; VÄRYNEN, S. Inclusive Education - consensus, conflict and challenges. In: JORNADES SOBRE LES NECESSITATS EDUCATIVES ESPECIALS A L'AULA, 2., sept./oct. 1999, Paris - Unesco.

SKLIAR, C. Pedagogia (improvável) da diferença - e se o outro não estivesse aí? Rio de Janeiro: DP\&A, 2003.

TRINDADE, A. L. da et al. (Org.). Multiculturalismo - mil e uma faces da escola. Rio de Janeiro: DP\&A, 1999.

Texto recebido em 12 jul. 2004

Texto aprovado em 23 out.2004 